\title{
The Methodology of Calculation the Quality of Life Index
}

\author{
S. Puskorius
}

\begin{abstract}
The goals of this paper are: to determine the stages of calculation of the quality of life index, to identify the quality of life index estimation branches, to distinguish main indicators which depict quality of each work out area, to introduce the corresponding mathematical models of each area, and present the method of calculation of the integral quality of life index. There are plenty of models used to measure the quality of population's life index, but as a rule they estimate influence of economical variables. Author in this paper tries to include much more indicators which cover all important dimensions. The originality of the paper includes determination of major dimensions, which define the quality of life index, two proposed mathematical models of calculation of the integral quality of the life index and specific indicators suitable for every situation, estimation of ways to measure weigh constituent coefficients, choosing the unit of measurement of any indicator, discussion of different ways of receiving the necessary information. Mentioned models are modern ones, not used before. Research is theoretical one. Author is going to make practical steps to use this methodology during the research participating in Project "Creation of system of measurement indicators and evolution model of the quality of life of Lithuanian population".
\end{abstract}

Index Terms-Indicators, integral quality of life index, mathematical models, quality of life index.

\section{INTRODUCTION}

The real state of the economy and the efficiency of economic policies in Lithuania are reflected by the people's quality of life indicators [1].

As the world's most famous economists (Nobel Prize winner Joseph Stiglitz [2], Amartya Sen [3], Paul Krugman [4], James Galbraith [5], etc.) confirm, the general economic indicators, such as GDP, inflation, the budget deficit are far from the evaluation of the real economic situation in the country. Consequently, it is necessary to have indicators, reflecting the full human life quality, covering various areas of human activity, including the most important of them.

First of all, it is necessary to define the areas where people can realize their possibilities at the different levels to use the services provided, to communicate efficiently, to participate in actual for them decision making processes, to feel safe, to live in dignity, and other areas.

\section{Mathematical Model to Calculate the Quality} OF LIFE INDEX

In assessing the diverse status of the country, it is

Manuscript received January 10, 2014; revised March 15, 2014

S. Puskorius is with the Mykolas Romeris University, Faculty of Politics and management, Ateities str. 20, LT-80303, Vilnius, Lithuania (e-mail: spusk@mruni.lt). necessary to move the centre of gravity towards human welfare and quality criteria, which include the following major dimensions: health status; employment and occupancy rate status; quality of lifetime work status; income status; consumption status; environment and accommodation status; education status; safety, law and order and corruption status; moral-ethical, spiritual, cultural values and leisure time status; gender equality status.

In proposed mathematical model the quality of life index is calculated by summing up of aggregated and weighted values of indicators mentioned above.

Suppose that each of mentioned status summarized indicators is determined and weigh coefficients of these indicators are known, thus the integral quality of life index can be calculated using the following formula:

$$
I=\sum_{i=1}^{10} a_{i} b_{i}
$$

where

$b_{1} ; a_{1}$-value of summarized health status indicator of population $\left(b_{1}\right)$ and weight coefficient of this indicator $\left(a_{1}\right)$ correspondingly;

$b_{2} ; a_{2}$-value of summarized employment and occupancy rate status of population $\left(b_{2}\right)$ and weight coefficient of this indicator $\left(a_{2}\right)$ correspondingly;

$b_{3} ; a_{3}$-value of summarized quality of lifetime work status indicator of population $\left(b_{3}\right)$ and weight coefficient of this indicator $\left(a_{3}\right)$ correspondingly;

$b_{4} ; a_{4}$-value of summarized income status indicator of population $\left(b_{4}\right)$ and weight coefficient of this indicator $\left(a_{4}\right)$ correspondingly;

$b_{5} ; a_{5}$-value of summarized consumption status indicator of population $\left(b_{5}\right)$ and weight coefficient of this indicator $\left(a_{5}\right)$ correspondingly;

$b_{6} ; a_{6}$-value of summarized environment and accommodation status indicator of population $\left(b_{6}\right)$ and weight coefficient of this indicator $\left(a_{6}\right)$ correspondingly;

$b_{7} ; a_{7}$-value of summarized education status indicator of population $\left(b_{7}\right)$ and weight coefficient of this indicator $\left(a_{7}\right)$ correspondingly;

$b_{8} ; a_{8}$-value of summarized safety, law and order and corruption status indicator of population $\left(b_{8}\right)$ and weight coefficient of this indicator $\left(a_{8}\right)$ correspondingly;

$b_{9} ; a_{9}$-value of summarized moral-ethical, spiritual, cultural values and leisure time status indicator of population $\left(b_{9}\right)$ and weight coefficient of this indicator $\left(a_{9}\right)$ correspondingly;

$b_{10} ; a_{10}$-value of summarized gender equality indicator of population $\left(b_{10}\right)$ and weight coefficient of this indicator $\left(a_{10}\right)$ correspondingly. 


\section{DETERMinAtion OF WEIGHT COEFFICIENTS}

It is necessary to state that one meets extremely difficult problem of determining the mentioned weight coefficients. In general scientists don't know how to determine weight coefficients and use only some recommendations. In our case it seems appropriate to follow such recommendations. First, it is appropriate to take advantage of the psychologist Maslow's hierarchical list of motives [6]. He found that there are five levels of human needs: physiological (food, clothes, rest, sex), security (to defend themselves from bandits, animals, cold, heat, etc.), communication (everyone needs to live and work in a group by fulfilling some of social needs), respect and recognition in the community, self-actualization (everyone seeks to achieve higher position, to have higher education level, better skills and to get acknowledged for his achievements).

According to Maslow, these needs are arranged in a strict hierarchy. The higher level needs for individual become important only when he has satisfied the lower-level needs.

Secondly, it should be recognized that the priorities of representatives of the different groups in society in different areas of performance may significantly vary, so it is necessary to evaluate the structure of the community, the number of members in each group, and to find a way to assess these differences. Thirdly, it is necessary to realize that the factors affecting the weight have a volatile character. Fourthly, we need to maximize the use of available statistical data, although in many cases there is a lack of some important indicators in the statistics, therefore it is necessary to invite experts, and use questionnaire for the survey of population.

It is necessary to select the suitable experts, who should determine the system of indicators for each area of activity, to suggest the ways how to range these indicators, which sources of information to use, how to determine the reliability of selected information, how to take into account the views of the population, and to address other relevant issues.

\section{INDICATORS USED IN EACH AREA}

During the evaluation of the influence of each area indicators on the integral quality of life index it is necessary to decide what indicators should be used in each area, to base their portfolio, to establish the values of each indicator enabling to make a decision on its qualitative impact, to identify the ways of measuring the values of each indicator. There is a complex set of issues to be tackled: to define who can formulate suitable set of indicators for each area, to identify the levels of significance of each indicator, to determine the ways how should be made a summary conclusion about the influence of each indicator being used to calculate the quality of life index. Again experts having perfect understanding of the characteristics of the operation in the specific area should be invited to propose the ways for collecting the necessary information, determining its relevance and the selection of possible sources of information, and assessing the validity and reliability of that information.

\section{Summarized QuALITY OF LIFE INDICATORS}

The value of summarized quality of life indicator of population in particular area can be calculated using the following formula:

$$
b_{i}=\sum_{j} c_{i j} d_{i j}
$$

where

$d_{i j} ; c_{i j}$-value of particular $(j)$ indicator $d_{i j}$ used for estimation of particular summarized (i) indicator of population and the weight coefficient $c_{i j}$ of this particular indicator correspondingly.

Index $(j)$ varies from one to the number of the selected indicators in each area.

\section{UNITS OF MEASUREMENT OF EACH INDICATOR}

It is important to choose the unit of measurement of each indicator. Because all indicators must have one and the same unit, or don't have any, it is recommended to select a unit of measure based on assumption if it is qualitative or quantitative one. If an indicator is measured by qualitative scale - the measurement unit may be score, if an indicator is measured by quantitative scale - it does not have the measurement unit, because its value is calculated as a ratio using the standardized formula:

$$
e_{i j}=\frac{d_{i j}-d_{0 i j}}{d_{0 i j}},
$$

where

$e_{i j}$-value of standardized indicator;

$d_{0 i j}$-value of the basic indicator chosen as a comparison level.

It is recommended to pick up the value of the basic indicator chosen as a comparison level in based on the average of this indicator among region countries, which are the subject of study. It may be European Union, the world or some parts of the world. Obviously that the value of standardized indicator may be positive, if an indicator in Lithuania is better than average of this indicators in countries under investigation, or negative in opposite case.

If an indicator is measured by qualitative scale the measurement unit score may have three or even five graduations; in the first case, it would be good, average and bad scores; in the second case it would be very good, good, average, bad and very bad scores.

\section{GRADUATIONS OF EACH QUALITY INDICATOR}

The graduations of each quality indicator should be labelled by some quantitative ratings, because the integral quality of the life index must be expressed in the digital form. What labels should be attached can be decided by the experts in dependence of the importance of any indicator. If qualitative assessments are obtained during survey of population by applying the five grade scale, the score one is 
applied, if she/he at least agrees with formulated question, and five, if she/he most agrees, than the average of assessments of the qualitative indicator may be calculated by formula

$$
r_{i j}=\frac{1}{N_{i j}} \sum_{k=1}^{5} k n_{k i j}
$$

where

$r_{i j}$-value of whatever indicator calculated using survey data of population;

$N_{i j}$-total number of respondents, who expressed their opinion replaying this question;

$k$-number of attached scores by respondents;

$n_{k i j}$ - number of respondents, who attached score $k$.

When the necessary indicators are selected and their values are determined, it is necessary to carry out a survey of the population and to compose the questionnaires reflecting the summary of the assessment of population opinions. Only when the residents express their opinion about each indicator one can determine if they really agree with this indicator for assessment of the population's quality of life, in particular, the index value.

It should be noted that both in Lithuania and elsewhere in the other countries statistical data systems are not quite enough widely developed, some necessary indicators for assessment population's quality of life are not gathering and estimated. In addition, the indicator's measuring technique is developed insufficiently. This problem is formulated in $\mathrm{S}$. Puškorius paper [7], based on the analysis of the efforts of scientists in the world to deal with it.

This problem is being investigated by many scientists, for example Poister [8] believed that the necessary measurements are possible only when the corresponding measurement systems are created.

The measurement system must be created individually for each indicator. The composition of such a system, the purpose and functions depend on what is necessary to measure, which area the indicator refers to, what stages of the process are investigated and on many other factors and their combinations.

Hence, the common features of the creating and functioning the measurement systems and specific features, must be created which fit to particular object, the goals of the evaluation, the environment, in which the system works, and other specific factors, influencing the perception and measurements.

An important stage in the functioning of the measurement system is associated with the data selection procedures, analysis of available information from different sources, the validity of the information and the reliability of the assessments, the application of the specific test parameters for the choice of the design methods, the validity and reliability of the data collected, the proper processing and presentation, the formulation of interim and final findings and other factors necessary to ensure the efficient use of data sampling and analysis. There are many problems needed to consider separately. Among them the following problems can be mentioned: whether the time for selection of information, price, and other efforts have adequate influence on the accuracy, reliability and objectivity of the results obtained; is it necessary to make special experiments, surveys, interviews, etc.; is it necessary to create a new test methods, suitable only for this specific indicator to examine and evaluate it [7].

The implementation phase of the measurement system encompasses many factors, among which may be mentioned the following: the approbation of the system, i.e. the perception if it may function properly; the introduction of the necessary data for the selection procedures; the establishment of the mechanism and the approbation of the data processing; the creating and approbation the procedures for the formulation of conclusions and recommendations; the inclusion of the recommendations of the measuring system in the decision-making procedures.

\section{CONCLUSION}

Proposed mathematical model to calculate the quality of life index estimates health status, employment and occupancy rate status, quality of lifetime work status, income status, consumption status, environment and accommodation status, education status, safety, law and order and corruption status, moral-ethical, spiritual, cultural values and leisure time status and gender equality status.

To calculate this index we need to determine appropriate weigh coefficients. It is suggested to use Maslow's hierarchical list of motives, experts and population opinion.

Composed formula to evaluate the value of summarized quality of life indicator of population in particular area.

Proposed the ways to choose and unify the units of measurement of each indicator used in particular area, to determine the graduations of each quality indicator.

It is pointed out that the measurement systems for calculation quality of life index are not enough developed worldwide and must be created individually for each indicator.

\section{ACKNOWLEDGMENT}

This research is funded by the European Social Fund under the Global Grant measure (No. VP1-3.1-ŠMM-07-K-03-032).

\section{REFERENCES}

[1] O. G. Rakauskienè and V. Servetkienė, Lietuvos gyventoju gyvenimo kokybè: dvidešimt metu rinkos ekonomikoje, Monografija, Vilnius: Mykolo Romerio universiteto leidyba, 2011, pp. 362.

[2] J. E. Stiglitz, Freefall - Free Markets and the Sinking of the Global Economy, New York: Penguin Books, 2010.

[3] A. Sen, Choice, Welfare and Measurement, Oxford: Basil Blackwell, 1982.

[4] P. Krugman, The Return of Depression Economics and the Crises of 2008, W.W. Norton \& Company, 2009.

[5] J. K. Galbright, The Socially Concerned Today, University of Toronto Press, 1998.

[6] A. A. Maslow, Theory of Human Motivation, N. Y., 1955.

[7] S. Puškorius, "Veiklos matavimų viešajame sektoriuje raida ir tendencijos," Viešoji politika ir administravimas, vol. 34, pp. 7-21, 2010 . 
[8] T. H. Poister, Measuring Performance in Public and Nonprofit Organizations, San Francisco: Jossey-Bass, 2003.

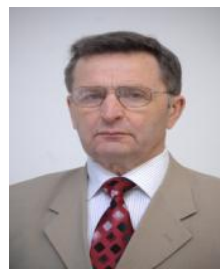

Stasys Puskorius was born in 1935 in District Skuodas Lithuanian Republic. He studied engineer of radar equipment in 1967. And he obtained doctor of technology sciences in 1974.

He is the chief scientific researcher honour professor emeritus of Mykolas Romeris University Vilnius Lithuania.

Prof. Dr. Stasys Puskorius is the member of editorial boards of many scientific journals. His research interests includes decision making theory and practice, performance audit theory and practice, grounding the personal size, investigation of structure, functions, responsibility of public institutions, analyses of government reform directions, evaluation of effectiveness of performance of public and private sector institutions. 